\title{
Brittle cornea syndrome: Disease-causing mutations in ZNF469 and two novel variants identified in a patient followed for 26 years
}

\author{
Pavlina Skalickaa,b, Louise F. Portere, ${ }^{c, d}$ Kristyna Brejchovaa ${ }^{a}$, Frantisek Malinkaa,e, Lubica Dudakova ${ }^{a}$, Petra Liskova ${ }^{a, b}$
}

\begin{abstract}
Aims. Brittle cornea syndrome (BCS) is a rare autosomal recessive disorder. The aim of this study was to review ZNF469 mutations associated with BCS type 1 to date and to describe an additional case of Czech/Polish background.

Methods. Whole genome sequencing was undertaken to identify the molecular genetic cause of disease in the proband. Sequence variants in ZNF469 previously reported as BCS type 1-causing were searched in the literature, manually curated and aligned to the reference sequence NM_001127464.2.

Results. The proband has been reviewed since childhood with progressive myopia and hearing loss. Aged 13 years had been diagnosed with Stickler syndrome. Aged 16.5 years, he developed acute hydrops in the left eye managed by corneal transplantation. At the age of 26 , he experienced right corneal rupture after blunt trauma, also managed by grafting. He had a number of secondary complications and despite regular follow-up and timely management, the right eye became totally blind and the left eye had light perception at the last follow-up visit, aged 42 . He was found to be a compound heterozygote for two novel mutations c.1705C >T; p.(Gln569*) and c.1402_1411del; p.(Pro468Alafs*31) in ZNF469. In total 22 disease-causing variants in ZNF469 have been identified, mainly in consanguineous families or endogamous populations. Only four probands, including the case described in the current study, harboured compound heterozygous mutations.

Conclusion. BCS occurs very rarely in outbred populations which may cause diagnostic errors due to poor awareness of the disease. Investigation into the underlying molecular genetic cause in patients with connective tissue disorders may lead to a re-evaluation of their clinical diagnosis.
\end{abstract}

Key words: ZNF469, deafness, brittle cornea syndrome, blindness, corneal rupture, penetrating keratoplasty

Received: January 25, 2019; Accepted: April 5, 2019; Available online: April 17, 2019

https://doi.org/10.5507/bp.2019.017

(c) 2020 The Authors; https://creativecommons.org/licenses/by/4.0/

${ }^{a}$ Research Unit for Rare Diseases, Department of Paediatrics and Adolescent Medicine, First Faculty of Medicine, Charles University and General University Hospital in Prague, Prague, Czech Republic

${ }^{b}$ Department of Ophthalmology, First Faculty of Medicine, Charles University and General University Hospital in Prague, Prague, Czech Republic

'St Paul's Eye Unit, The Royal Liverpool University Hospital, Prescot St, Liverpool, UK

${ }^{d}$ Department of Eye and Vision Science, Institute of Ageing and Chronic Disease, University of Liverpool, Liverpool, UK

eDepartment of Computer Science, Czech Technical University in Prague, Prague, Czech Republic

Corresponding author: Petra Liskova, e-mail: petra.liskova@lf1.cuni.cz

\section{INTRODUCTION}

Brittle cornea syndrome (BCS) is a rare generalized connective tissue disorder inherited as an autosomal recessive trait. Clinical ocular features include fragile thin ectatic corneas and blue sclerae. Variable commonly associated extraocular manifestations comprise skeletal and/or connective tissue abnormalities, such as joint hypermobility with occasional dislocations, kyphoscoliosis, hyperlaxity of the skin, dental abnormalities and hearing loss which develops in around one third of cases $^{1,2}$.

Mutations within two genes ZNF469 (ref., ${ }^{2,3}$ ) and PRDM5 (ref.,5) are known to be associated with BCS type 1 (BCS1; MIM \#229200) and type 2 (BCS2; MIM \#614170), respectively. The disease mechanism remains unclear. Both encoded proteins ZNF469 and PRDM5 are transcription factors regulating extracellular matrix components, particularly fibrillar collagens suggesting involvement in the same pathway ${ }^{3,5,6}$.
In this review we summarize and evaluate for pathogenicity using recent bioinformatics tools all variants in ZNF469 previously reported as BCS1-causing including two novel ZNF469 mutations identified in a case of Czech/Polish descent under ophthalmic review for 26 years.

\section{MATERIALS AND METHODS}

The study was approved by the Ethics committee of General University in Prague and adhered to the Declaration of Helsinki. Informed consents were signed prior to the start of all investigations.

DNA from the proband and participating family members was extracted from a venous blood sample using the Gentra Puregene blood kit (Qiagen, Hilden, Germany) and analysed by genome sequencing using a TruSeq Nano DNA library preparation kit and a HiSeq X Ten sequencer 


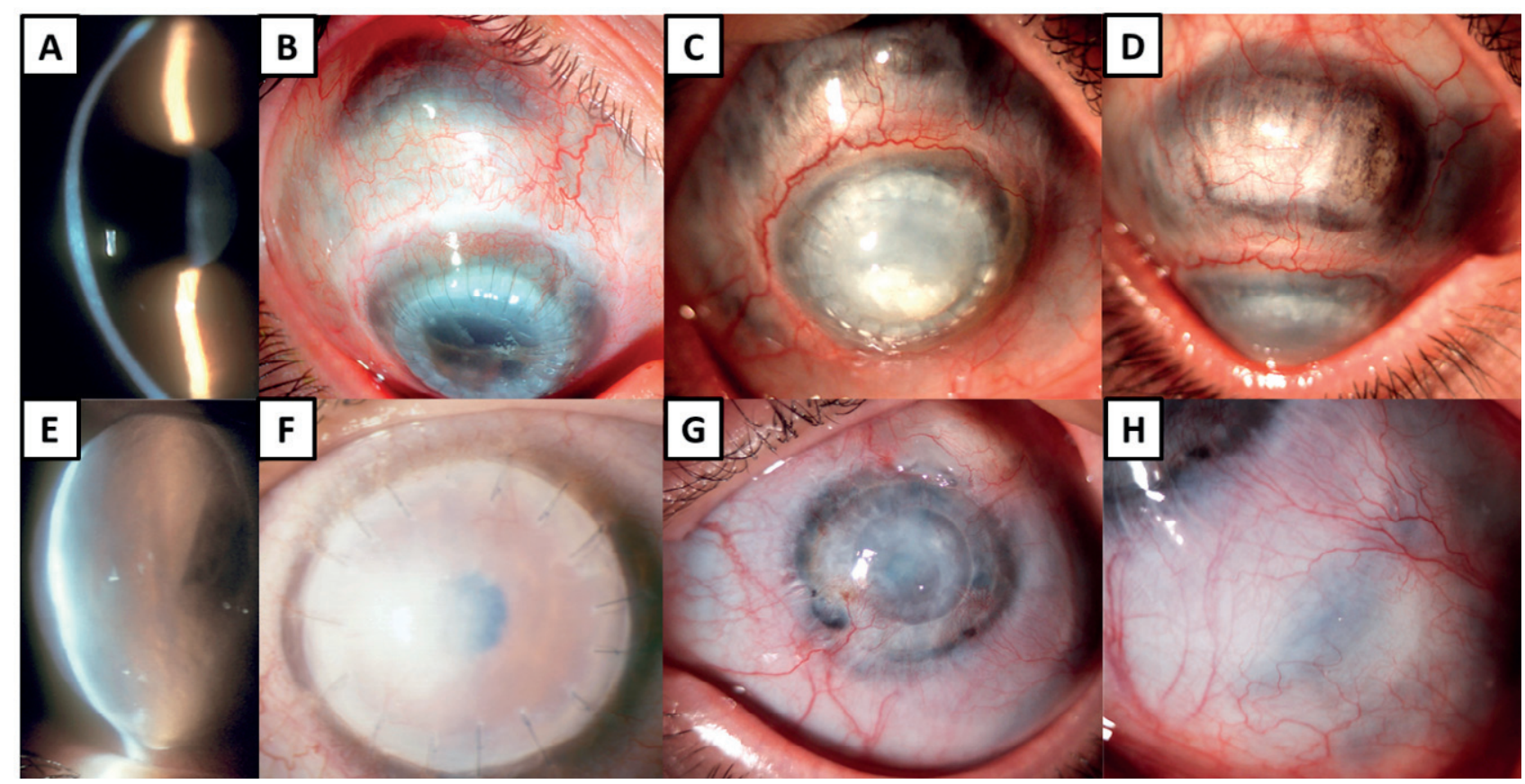

Fig. 1. Ocular findings in a patient with brittle cornea syndrome. (A) Narrow slit-beam view of the right cornea with ectasia (age 16.5 years), (B) right eye after tectonic penetrating keratoplasty, note blue sclerae superior from the corneal limbus (age 26.5), (C) opaque right graft with lipoid keratopathy and progression of scleral thinning, (D) in detail (age 42). (E) Acute hydrops in the left eye (age 16.5); (F) left graft failure (age 17.5), (G) left eye with a vascularized graft (age 42), (H) detail of blue sclerae (age 42).
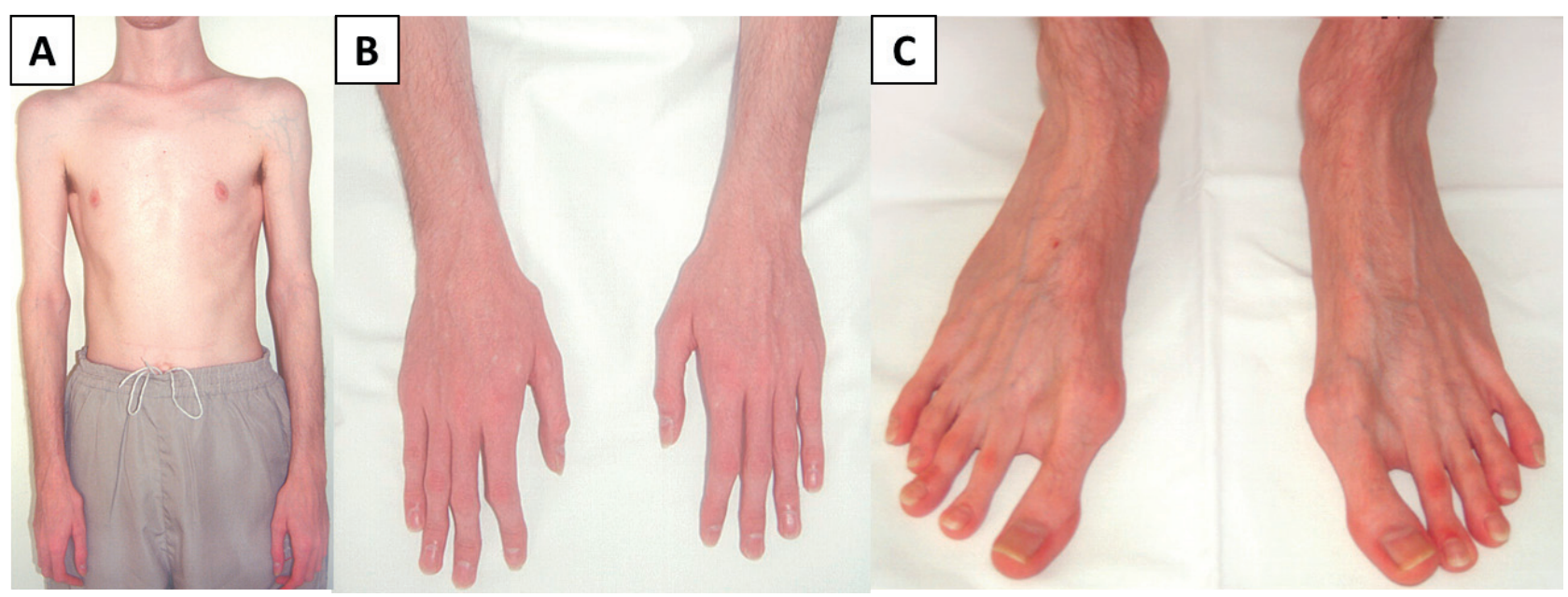

Fig. 2. Physical appearance of the patient with brittle cornea syndrome. (A) asthenic habitus (age 26); (B) hands with clinodactyly (age 26); (C) feet with hallux valgus (age 26).

(Illumina). FASTQ reads were aligned to the GRCh38/ hg38 human reference sequence using the BurrowsWheeler Alignment tool ${ }^{7}$. Variant calling was performed with HaplotypeCaller ${ }^{8}$. Sequence changes with a minor allele frequency $<0.005$ in ZNF469 and PRDM5 were prioritized for further evaluation. Conventional Sanger sequencing was applied to show segregation of the detected mutation within the family?

Sequence variants previously reported as causing BCS1 were searched in the literature, manually curated and aligned to the reference sequence NM_001127464.2. Missense variants were subjected to in silico analysis using 6 different tools. The population frequency of the variants was retrieved from the Genome Aggregation
Database (gnomAD), providing sequencing data from more than 138,000 unrelated individuals of various ethnic backgrounds ${ }^{10}$, and 4,528 Czech control chromosomes available through the projects of the National Center for Medical Genomics (https://ncmg.cz/en).

\section{RESULTS}

\section{CASE REPORT}

The proband of Czech/Polish descent was under ophthalmic review from his $3^{\text {rd }}$ birthday because of progressive myopia. According to his clinical notes, he was 
Table 1. Ocular surgeries performed in the proband reviewed for 26 years.

\begin{tabular}{lllllll}
\hline Eye & $\begin{array}{l}\text { Age } \\
\text { (years) }\end{array}$ & Procedure & Reason & $\begin{array}{l}\text { Preoperative } \\
\text { BCVA }\end{array}$ & $\begin{array}{l}\text { Postoperative } \\
\text { BCVA (3 months } \\
\text { after surgery) }\end{array}$ & Comment \\
\hline \multirow{2}{*}{26.0} & Tectonic PK & $\begin{array}{l}\text { Large corneal perforation } \\
\text { after blunt trauma }\end{array}$ & LP & 0.16 & $\begin{array}{l}\text { Graft size 8.5 mm, aphakia } \\
\text { (lens lost during trauma) }\end{array}$ \\
RE & 26.0 & AMT & Wound leakage & 0.16 & 0.16 & \\
& 26.5 & PPV + SO & Retinal detachment & 0.10 & 0.25 & Graft size 9.0 mm \\
& 28.5 & CCK & Secondary glaucoma & LP & LP & Performed 11 days after rePK \\
\hline & 16.5 & PK & Corneal hydrops & LP & 0.16 & Graft size 6.2 mm \\
\hline
\end{tabular}

AMT - amniotic membrane transplantation; BCVA - best corrected visual acuity (measured on Snellen charts and extrapolated to decimal values); CCK - cyclocryocoagulation; LE - left eye; LP - light projection; PK - penetrating keratoplasty; PPV - pars plana vitrectomy; RE - right eye; rePK - repeated penetrating keratoplasty; SO - silicone oil tamponade; TE - trabeculectomy

Table 2. Summary of ZNF469 mutations and individual families with brittle cornea syndrome reported to date.

\begin{tabular}{|c|c|c|c|c|c|c|c|}
\hline DNA level & Protein level & $\begin{array}{c}\text { No of } \\
\text { affected } \\
\text { subjects/with } \\
\text { hearing loss }\end{array}$ & $\begin{array}{c}\text { No. of } \\
\text { families }\end{array}$ & Origin & Zygosity & $\begin{array}{l}\text { Consangu- } \\
\text { inity }\end{array}$ & Ref. \\
\hline $\begin{array}{l}\text { c.1402_1411del } \\
\text { c.1705C }>\mathrm{T}\end{array}$ & $\begin{array}{l}\text { p. }(\text { Pro468Alafs*31) } \\
\text { p. }(\text { Gln569*) }\end{array}$ & $1 / 1$ & 1 & $\begin{array}{l}\text { Caucasian Czech/ } \\
\text { Polish }\end{array}$ & $\begin{array}{l}\text { Compound } \\
\text { HET }\end{array}$ & $\mathrm{N}$ & $\begin{array}{l}\text { Current } \\
\text { study }\end{array}$ \\
\hline $\begin{array}{l}\text { c.1963dup } \\
\text { c. 6360dup }\end{array}$ & $\begin{array}{l}\text { p. }(\text { His } 655 \text { Profs*83) } \\
\text { p. }(\text { Gln } 2121 \text { Alafs*42) }\end{array}$ & $1 / 0$ & 1 & Not provided & $\begin{array}{l}\text { Compound } \\
\text { HET }\end{array}$ & $\mathrm{N}$ & 17 \\
\hline c. $2029 \mathrm{G}>\mathrm{T}$ & p. $\left(\right.$ Gly $\left.677^{*}\right)$ & $2 / 0$ & 1 & Saudi Arabian & HOM & $\mathrm{Y}$ & 1,13 \\
\hline c. $2150 \mathrm{del}$ & p. $($ Phe 717 Serfs* 15$)$ & $3 / 0$ & 2 & Saudi Arabian & HOM & $\mathrm{Y} / 1, \mathrm{~N} / 1^{\#}$ & $1,13^{\#}, 18$ \\
\hline c. $3220 \mathrm{G}>\mathrm{T}$ & p. (Glu 1074*) & $1 / 1$ & 1 & Yemenish & HOM & $\mathrm{Y}$ & 1,13 \\
\hline c. $3392 \mathrm{del}$ & p.(Gly1131Alafs*105) & $1 / 1$ & 1 & Indian & HOM & $\mathrm{Y}$ & 13 \\
\hline c. $4174 \mathrm{G}>\mathrm{T}$ & p. $($ Glu $1392 *)$ & $2 / 0$ & 1 & Syrian & HOM & Y & 19 \\
\hline c. $5269 \mathrm{C}>\mathrm{T}$ & p. $\left(\mathrm{Gln} 1757^{*}\right)$ & $3 / 3$ & 2 & Syrian & HOM & $\mathrm{Y}$ & 1,13 \\
\hline c. 5704del & p. $(\mathrm{Gln} 1902 \operatorname{Argfs} * 6)$ & $1 / 1$ & 1 & Caucasian British & Compound & $\mathrm{N}$ & 13 \\
\hline c.5704dup & p. (Gln1902Profs*133) & & & & HET & & \\
\hline c.5943del & p.(Gly1983Alafs*16) & 6/NA & 4 & Tunisian Jewish & HOM & $\mathrm{Y} / 3, \mathrm{~N} / 1^{\#}$ & 3,20 \\
\hline c. $6360 \mathrm{del}$ & p. $(G \ln 2121 S e r f * 51)$ & $1 / 0$ & 1 & Pakistani & HOM & $\mathrm{Y}$ & 1,13 \\
\hline $\begin{array}{l}\text { c. } 6644 \text { delA } \\
\text { deletion of 1q24.1 } \\
\text { including ZNF469 }\end{array}$ & $\begin{array}{l}\text { p.(Asp2215Alafs*8). } \\
\text { p.? }\end{array}$ & $1 / 0$ & 1 & Caucasian & $\begin{array}{l}\text { Compound } \\
\text { HET }\end{array}$ & $\mathrm{N}$ & 12 \\
\hline c.6563del & p. $(\mathrm{Gln} 2188 \operatorname{Argfs} * 21)$ & $2 / 0$ & 1 & Syrian & HOM & $\mathrm{Y}$ & 1,13 \\
\hline c.8817_8830dup & p.(Glu2944Glyfs*50) & $8 / 4$ & 2 & Saudi Arabian & HOM & $\mathrm{Y}$ & $1,13,21$ \\
\hline c.9399del & p. $($ His3134Thrfs*20) & $1 / 0$ & 1 & Saudi Arabian & HOM & Y & 1,13 \\
\hline c.9531del & p. $(\mathrm{G} \ln 3178 \operatorname{Argfs} * 23)$ & $6 / \mathrm{NA}$ & 1 & Palestinian & HOM & $\mathrm{Y}$ & 3 \\
\hline c. $10016 \mathrm{G}>\mathrm{A}$ & p.(Cys3339Tyr) & $2 / 2$ & 1 & Norwegian & HOM & Y & 2 \\
\hline c. $10022 \mathrm{G}>\mathrm{C}$ & p.(Arg3341Pro) & $1 / 0$ & 1 & Syrian & HOM & $\mathrm{Y}$ & 1,13 \\
\hline
\end{tabular}

HOM = homozygous, HET = heterozygous, $\mathrm{Y}=$ yes, $\mathrm{N}=$ no, $\mathrm{NA}=$ not available

"common founder with other families carrying the same mutation

All mutations were curated based on original publications and are listed according to the reference sequence NM_001127464.2. Recommendations of Human Genome Variation Society were used for description. Information on origin was mined from published reports.

Table 3. In silico analysis of two missense variants in ZNF469.

\begin{tabular}{|c|c|c|c|c|c|c|c|}
\hline DNA level & Protein level & PolyPhen2 (ref. ${ }^{22}$ ) & $\begin{array}{l}\text { PROVEAN } \\
\left(\text { ref. }^{23}\right)\end{array}$ & SIFT $\left(\right.$ ref. $\left.^{23}\right)$ & MutPred2 (ref. $\left.{ }^{24}\right)$ & $\begin{array}{l}\text { Mutation Taster } \\
\left(\text { ref. }^{25}\right)\end{array}$ & $\begin{array}{l}\text { SNP\&GO } \\
\left(\text { ref. }^{26}\right)\end{array}$ \\
\hline c.10016G>A & p.(Cys3339Tyr) & Probably damaging & Disease & Damaging & Disease causing & Disease causing & Disease \\
\hline c. $10022 \mathrm{G}>\mathrm{C}$ & p.(Arg3341Pro) & Probably damaging & Neutral & Damaging & Disease causing & Polymorphism & Disease \\
\hline
\end{tabular}

Both mutations were detected in a compound heterozygous state with a truncating mutation in patients with BCS1 (NM_001127464.2). 
A

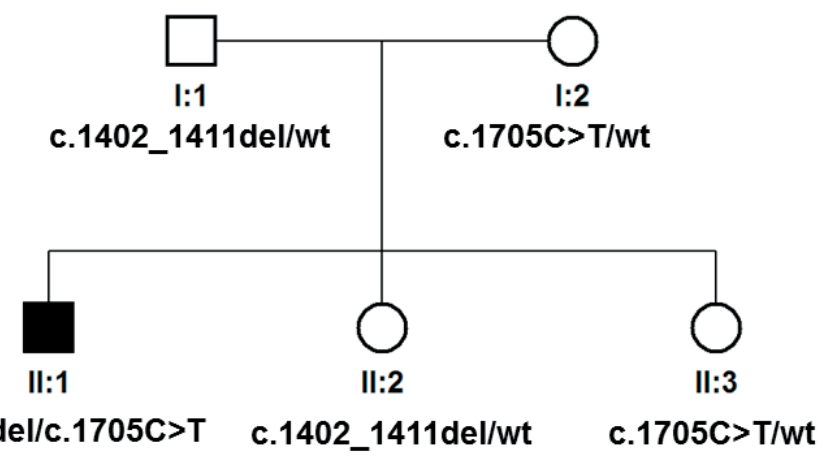

B

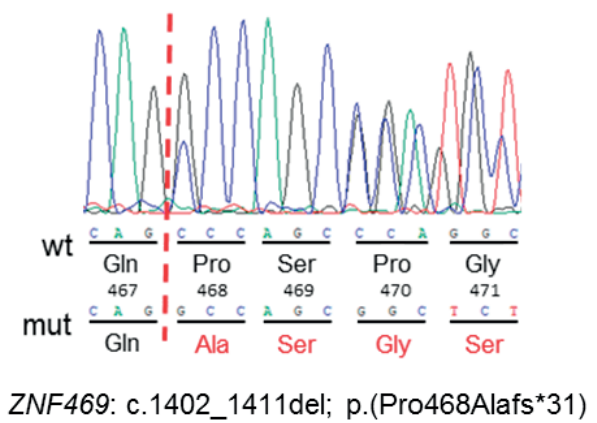

C

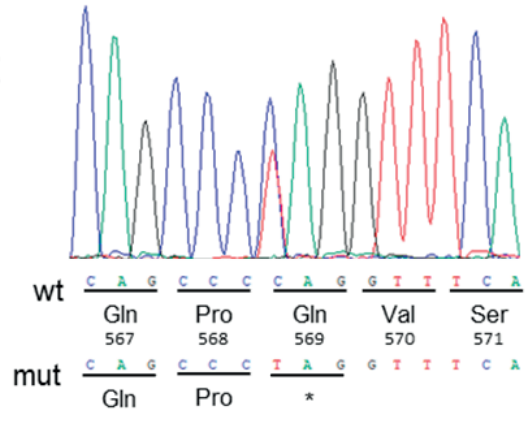

ZNF469: c. $1705 C>T ;$ p. $\left(G \ln 569^{\star}\right)$

Fig. 3. Pedigree and results of molecular genetic testing. (A) Pedigree of the investigated family, sequence chromatograms of the heterozygous mutations identified in ZNF469 (B) c.1402_1411del and (C) c.1705C $>$ T. Wild type is referred as "wt".

diagnosed with bilateral corneal ectasia before the age of 13 years. Best corrected visual acuity (BCVA) at the age of 16 was 0.1 (Snellen decimal conversion) with -23 dioptre sphere (DS) in the right eye, and 0.06 with -23 DS x -4.0 dioptre cylinder in the left eye. At the age of 16.5 years he was referred to the Department of Ophthalmology, General University Hospital in Prague, with acute corneal hydrops in the left eye (Fig. 1E). Blue sclerae were also noticed bilaterally (Fig. 1B, H). Right cornea was ectatic (Fig. 1A). No other abnormalities of iris, pupil, lens or retina were noted. Penetrating keratoplasty was performed two months later in view of persistence of the corneal edema and light perception visual acuity in the affected eye. Unfortunately, the patient suffered from immunological rejection and graft failure (Fig. 1F). Two repeated keratoplasties were therefore performed at the age of 17.5 and 20 years complicated by increased intraocular pressure (IOP) necessitating trabeculectomy. Eighteen months after the third keratoplasty, BCVA was 0.16 in the left eye. Thereafter the graft gradually failed (Fig. $1 \mathrm{G}$ ) and 23 years following his examination (now aged 42) BCVA in the left eye was light perception. IOP remained controlled.

At the age of 26, the patient experienced right corneal rupture with lens dislocation after blunt trauma. Tectonic penetrating keratoplasty was performed. Five months after the surgery, the right retina detached and the patient underwent pars plana vitrectomy and silicone oil tamponade. Unfortunately, uncontrollable secondary glaucoma caused progressive BCVA decline. The corneal graft in the right also failed and became opaque (Fig. 1C). Since the age of 32 , the right eye was totally blind. Progression of scleral ectasia was documented (Fig. 1B,C,D). Table 1 lists all surgeries the patient underwent since the age of 16.5 years.

In addition, the proband had been followed up since childhood (11 years of age) for sensorineural hearing loss, managed with a hearing aid. Repeated audiometry confirmed the presence of moderate symmetrical nonprogressive impairment in both ears with a loss in the range of 45-65 $\mathrm{dB}$. Mild worsening was observed with age and deemed to be age-associated.

Transthoracic echocardiography was performed at the age of 17 and 26 years. Mitral and tricuspid valve insufficiencies were noted but not deemed functionally important. Incomplete right bundle branch block was also detected on electrocardiography and considered benign, not requiring treatment. Aged 26 years the patient's height was $190 \mathrm{~cm}$ and his weight was $60 \mathrm{~kg}$, with concomitant mild kyphoscoliosis, clinodactyly and hallux valgus (Fig. 2). No joint subluxations, fractures, abnormal contractures or severe bone deformities were found. No skin striae, excessive scarring, bruising or abnormal laxity were observed. At the age of 31, the proband underwent surgery for right scrotal hernia. Of note, he also suffered from excessive dental caries since childhood. Details of dental examinations were however unavailable.

Importantly, since the age of 13 he had been considered to be a de novo case of Stickler syndrome. This diagnosis remained unchallenged until the age of 40, when a clinical diagnosis of BCS based on careful review of his past clinical notes was suspected.

Molecular genetic diagnosis uncovered com- 
pound heterozygosity for c. $1705 \mathrm{C}>\mathrm{T}$; p. $\left(\mathrm{Gln} 569^{*}\right)$ and c.1402_1411del; p.(Pro468Alafs*31) in ZNF469 (Fig.3), absent from gnomAD as well as from white Czech control chromosomes, confirming BCS1. As truncating mutations have been previously associated with BCS1 (Table 2 ), these variants were considered pathogenic. Consistent with autosomal recessive disease, both parents were heterozygous carriers of each detected variants. Two unaffected sisters were also heterozygous carriers (Fig. 3).

\section{Summary of ZNF469 mutations causing BCS1}

Including this study, there are 22 different sequence variants reported as pathogenic in 24 families with more than 40 family members affected by BCS1 (Table 2). Only four probands were compound heterozygotes, the rest were homozygotes.

None of the mutations had an entry in gnomAD. Sixteen reported variants are predicted to result in the interruption of translation, consequently leading either to a truncation of the encoded protein, or degradation of aberrant transcripts by nonsense-mediated mRNA decay $^{11}$. One mutation was a large deletion encompassing the whole ZNF469 gene. Two variants were missense mutations ${ }^{1,12,13}$. Pathogenicity predictions using six software tools supported the disease-causing role of the two missense mutations (Table 3 ).

One additional variant reported as disease-causing c. $7424 \mathrm{C}>\mathrm{A}$; p.(Ala2475Glu) (ref. ${ }^{13}$ ) was discarded because of its high prevalence in the general population (minor allele frequency 0.07422 , with 567 homozygotes reported as per gnomAD), not matching the rarity of BCS1.

\section{DISCUSSION}

BCS1 is an ultra-rare disease. In addition to a comprehensive curation and summary of all 22 disease-causing mutations in ZNF469 associated with BCS1 reported to date, we present a case harbouring two novel pathogenic variants detected by genome sequencing.

Analysis using current bioinformatic tools, especially interrogation of publicly available minor allele frequencies, allowed us to dismiss one ZNF469 variant previously associated with BCS1 highlighting the general fact that there is a need of re-evaluation of mutational findings published before the era of large datasets. BCS1 has been caused by homozygous mutations in the great majority of families, which is consistent with consanguinity and/ or marriages within endogamous populations. The function of ZNF469 has not been fully resolved, however the importance of the protein on corneal structure and development has been recently confirmed, showing association with keratoconus and central corneal thickness ${ }^{9,14}$.

Although the phenotype in our proband was typical it took more than two decades to make the correct diagnosis. His clinical course confirms the fact that management of corneal rupture in BCS is difficult and outcomes are usually unsatisfactory despite state-of-the-art treatment ${ }^{15,16}$.
It is therefore of utmost importance to recognize BCS early, in order to apply preventive measures. As a part of our long-term follow-up we have also documented sensorineural hearing impairment with no progression other than age-related mild decline.

\section{CONCLUSION}

BCS1 occurs very rarely in outbred populations which may cause diagnostic errors due to poor awareness of the disease. Molecular genetic analysis evolved to be an essential part of the diagnostic process in many rare diseases including BCS, and in some cases, it may even lead after many years to a correction of the clinical diagnosis.

Acknowledgement: This work was supported by GAUK 36417. Institutional support was provided by UNCE 204011, SVV 260367/2017 and PROGRES Q26/LF1 programs of the Charles University. LFP is a clinical lecturer funded by NIHR. FM was supported by OP VVV MEYS funded project CZ.02.1.01/0.0/0.0/16_019/0000 765 "Research Center for Informatics". We thank The National Center for Medical Genomics (LM2015091) providing ethnically matched population frequency data (project CZ.02.1.01/0.0/0.0/16_013/0001634).

Author contributions: PS: manuscript writing, data collection; LFP: manuscript writing, data collection and analysis, KB: manuscript writing, figure preparation and literature search, FM: manuscript writing, statistical analysis, LD: manuscript writing, figure preparation and PL manuscript writing, study design.

Conflict of interest statement: The authors state that there are no conflicts of interest regarding the publication of this article.

\section{REFERENCES}

1. Al-Hussain H, Zeisberger SM, Huber PR, Giunta C, Steinmann B. Brittle cornea syndrome and its delineation from the kyphoscoliotic type of Ehlers-Danlos syndrome (EDS VI): report on 23 patients and review of the literature. Am J Med Genet A 2004;124A:28-34.

2. Christensen AE, Knappskog PM, Midtbo M, Gjesdal CG, Mengel-From J, Morling N, Rødahl E, Boman H. Brittle cornea syndrome associated with a missense mutation in the zinc-finger 469 gene. Invest Ophthalmol Vis Sci 2010;51:47-52.

3. Abu A, Frydman M, Marek D, Pras E, Nir U, Reznik-Wolf H, Pras E. Deleterious mutations in the Zinc-Finger 469 gene cause brittle cornea syndrome. Am J Hum Genet 2008;82:1217-22.

4. Burkitt Wright EMM, Spencer HL, Daly SB, Manson FDC, Zeef LAH, Urquhart J, Zoppi N, Bonshek R, Tosounidis I, Mohan M, Madden C, Dodds A, Chandler KE, Banka S, Au L, Clayton-Smith J, Khan N, Biesecker LG, Wilson M, Rohrbach M, Colombi M, Giunta C, Black GCM. Mutations in PRDM5 in brittle cornea syndrome identify a pathway regulating extracellular matrix development and maintenance. Am J Hum Genet 2011;88:767-77.

5. Porter LF, Gallego-Pinazo R, Keeling CL, Kamieniorz M, Zoppi N Colombi M, Giunta C, Bonshek R, Manson FD, Black GCM. Bruch's membrane abnormalities in PRDM5-related brittle cornea syndrome. Orphanet J Rare Dis 2015;10:145.

6. Galli GG, Honnens de Lichtenberg K, Carrara M, Hans W, Wuelling M, Mentz B, Multhaupt HA, Fog CK, Jensen KT, Rappsilber J, Vortkamp A, Coulton L, Fuchs H, Gailus-Durner V, Hrabě de Angelis 
M, Calogero RA, Couchman JR, Lund. Prdm5 regulates collagen gene transcription by association with RNA polymerase II in developing bone. PLoS Genet 2012;8:e1002711.

7. Li H, Durbin R. Fast and accurate long-read alignment with BurrowsWheeler transform. Bioinformatics 2010;26:589-95.

8. Van der Auwera GA, Carneiro MO, Hartl C, Poplin R, Del Angel G, Levy-Moonshine A, Jordan T, Shakir K, Roazen D, Thibault J, Banks E, Garimella KV, Altshuler D, Gabriel S, DePristo MA. From FastQ data to high confidence variant calls: the Genome Analysis Toolkit best practices pipeline. Curr Protoc Bioinformatics 2013;43:11.10.1-11.10.33. doi: 10.1002/0471250953.bi1110s43

9. Lechner J, Porter LF, Rice A, Vitart V, Armstrong DJ, Schorderet DF, Munier FL, Wright AF, Inglehearn CF, Black GC, Simpson DA, Manson $F$, Willoughby CE. Enrichment of pathogenic alleles in the brittle cornea gene, ZNF469, in keratoconus. Hum Mol Genet 2014;23:55275535.

10. Lek M, Karczewski KJ, Minikel EV, Samocha KE, Banks E, Fennell T, O'Donnell-Luria AH, Ware JS, Hill AJ, Cummings BB, Tukiainen T, Birnbaum DP, Kosmicki JA, Duncan LE, Estrada K, Zhao F, Zou J, Pierce-Hoffman E, Berghout J, Cooper DN, Deflaux N, DePristo M, Do, Flannick J, Fromer M, Gauthier L, Goldstein J, Gupta N, Howrigan D, Kiezun A, Kurki MI, Moonshine AL, Natarajan P, Orozco L, Peloso GM, Poplin R, Rivas MA, Ruano-Rubio V, Rose SA, Ruderfer DM, Shakir K, Stenson PD, Stevens C, Thomas BP, Tiao G, Tusie-Luna MT, Weisburd B, Won HH, Yu D, Altshuler DM, Ardissino D, Boehnke M, Danesh J, Donnelly S, Elosua R, Florez JC, Gabriel SB, Getz G, Glatt SJ, Hultman CM, Kathiresan S, Laakso M, McCarroll S, McCarthy MI, McGovern D, McPherson R, Neale BM, Palotie A, Purcell SM, Saleheen D, Scharf JM, Sklar P, Sullivan PF, Tuomilehto J, Tsuang MT, Watkins HC, Wilson JG, Daly MJ, MacArthur DG; Exome Aggregation Consortium. Analysis of protein-coding genetic variation in 60,706 humans. Nature 2016;536:285-91.

11. Hug N, Longman D, Caceres JF. Mechanism and regulation of the nonsense-mediated decay pathway. Nucleic Acids Res 2016;44:148395.

12. Ramappa M, Wilson ME, Rogers RC, Trivedi RH. Brittle cornea syndrome: a case report and comparison with Ehlers Danlos syndrome. J AAPOS 2014;18:509-11.

13. Rohrbach M, Spencer HL, Porter LF, Burkitt-Wright EM, Bürer C, Janecke A, Bakshi M, Sillence D, Al-Hussain H, Baumgartner M Steinmann B, Black GC, Manson FD, Giunta C. ZNF469 frequently mutated in the brittle cornea syndrome (BCS) is a single exon gene possibly regulating the expression of several extracellular matrix components. Mol Genet Metab 2013;109:289-95.

14. Davidson $A E$, Borasio $E$, Liskova $P$, Khan $A O$, Hassan $H$, Cheetham ME, Plagnol V, Alkuraya FS, Tuft SJ, Hardcastle AJ. Brittle cornea syn- drome ZNF469 mutation carrier phenotype and segregation analysis of rare ZNF469 variants in familial keratoconus. Invest Ophthalmol Vis Sci 2015;56:578-86.

15. Burkitt Wright EM, Porter LF, Spencer HL, Clayton-Smith J, Au L, Munier FL, Smithson S, Suri M, Rohrbach M, Manson FD, Black GC. Brittle cornea syndrome: recognition, molecular diagnosis and management. Orphanet J Rare Dis 2013;8:68.

16. Izquierdo L, Jr., Mannis MJ, Marsh PB, Yang SP, McCarthy JM. Bilatera spontaneous corneal rupture in brittle cornea syndrome: a case report. Cornea 1999;18:621-4.

17. Menzel-Severing J, Meiller R, Kraus C, Trollmann R, Atalay D. Brittle cornea syndrome type 1 caused by compound heterozygosity of two mutations in the ZNF469 gene. Ophthalmologe 2018 Oct 18. doi: 10.1007/s00347-018-0796-8 [Epub ahead of print] [Article in German]

18. Khan AO, Aldahmesh MA, Alkuraya FS. Brittle cornea without clinically-evident extraocular findings in an adult harboring a novel homozygous ZNF469 mutation. Ophthalmic Genet 2012;33:257-9.

19. Khan AO, Aldahmesh MA, Mohamed JN, Alkuraya FS. Blue sclera with and without corneal fragility (brittle cornea syndrome) in a consanguineous family harboring ZNF469 mutation (p.E1392X). Arch Ophthalmol 2010;128:1376-9.

20. Abu A, Frydman M, Marek D, Pras E, Stolovitch C, Aviram-Goldring A, Rienstein S, Reznik-Wolf H, Pras E. Mapping of a gene causing brittle cornea syndrome in Tunisian jews to $16 q 24$. Invest Ophthalmol Vis Sci 2006;47:5283-7.

21. Al-Owain M, Al-Dosari MS, Sunker A, Shuaib T, Alkuraya FS. Identification of a novel ZNF469 mutation in a large family with Ehlers-Danlos phenotype. Gene 2012;511:447-50.

22. PolyPhen-2. Prediction of functional effects of human nsSNPs. http:// genetics.bwh.harvard.edu/pph2/ (accessed12/2018).

23. PROVEAN (Protein Variation Effect Analyzer): a software tool which predicting whether an amino acid substitution or indel has an impact on the biological function of a protein. It also shows SIFT predictions when precomputed scores are available. http://provean. jcvi.org/protein_batch_submit.php?species=human (accessed 12/2018).

24. MutPred2. Predict the pathogenicity of amino acid substitutions and their molecular mechanisms. http://mutpred.mutdb.org/\#qform

25. Mutation Taster: The free web-based application to evaluate DNA sequence variants for their disease-causing potential. http://www. mutationtaster.org/ (accessed 12/2018)

26. SNP\&GO: Predicting disease associated variations using GO terms http://snps.biofold.org/snps-and-go/snps-and-go.html (accessed $12 / 2018)$ 